\title{
Good Practice Case Study on HIV Prevention Treatment, Support and Care to Adolescents and Young People in the Western Cape, Beaufort West, South Africa: Profiling the Out of School Youth Project of Partners in Sexual Health (PSH) Targeted at Ages 15-24
}

Gerda Erasmus ${ }^{1 *}$ and Leon Swartz ${ }^{2}$

${ }^{1}$ Population and Development Research, Department of Social Development, Republic of South Africa Pretoria

${ }^{2}$ National Director Population Development Research

\begin{abstract}
The good practice case study was undertaken in 2015 and mostly focussed on out of school youth with regard to adolescent sexual reproductive health and rights and HIV and Aids prevention. This study used a mixed method where both the quantitative as well as the qualitative research method were utilised and where the latter was the dominant method. The research focus on the target beneficiaries between the ages 15-24 and the services they received from Partners in Sexual Health (PSH). The findings indicate that this group are very early sexual active. The research has further established that when it comes to Sexual Reproductive Health and Rights (SRHR) there is a huge need for youth friendly services and cognisance need to be taken of the needs of young people, which is not being identified and addressed fully. While the exact impact on beneficiaries of the Out of School Project has not been measured, there is considerable evidence of a positive impact on beneficiaries as reflected by the respondent's comments. According to observations made by the key informants the uptake of the Out of School Project was excellent. The study concluded by presenting a list of recommendations.
\end{abstract}

Keywords: Sexual reproductive health and rights; HIV and AIDS; Out of school youth; Gender base violence; Peer advisers

\section{Introduction}

This research project formed part of a larger six-year, two-phased regional initiative, entitled 'Safeguard Young People in Southern Africa Programme' (SYP). The regional programme is being undertaken in eight Southern African countries (Botswana, Lesotho, Malawi, South Africa, Namibia, Swaziland, Zambia and Zimbabwe), and is coordinated by the United Nations Population Fund (UNFPA) Regional Office East and Southern Africa (ESARO).

The broad aim of the SYP is to improve and expand HIV prevention and sexual and reproductive health and rights (SRHR) for adolescents and youth, aged between 10 and 24 . In addition, the programme seeks to empower adolescents and young people to protect themselves from sexually transmitted infections (STIs), including HIV, unplanned and unwanted pregnancies, unsafe abortions, early marriages, gender-based violence and harmful cultural practices, whilst promoting genderequitable norms.

South Africa, in particular, is one of the countries with a larger proportion of young people in the population. South Africa has a relatively youthful population, with more than two thirds of the population younger than 35 years of age [1]. Like in many other countries, young people in South Africa are at risk of physical and psychological trauma resulting from sexual abuse, gender-based violence, and other forms of physical violence, accidents, sexual and reproductive health disorders, such as STIs, HIV and AIDS, unwanted pregnancies, and related complications [2]. Different studies have also shown that in South Africa and in sub-Saharan Africa, young people engaged in early sexual debut have multiple sexual partners and tend to be increasingly engaged in pre-marital sexual activities [3].

The realisation of the magnitude of reproductive health problems faced by the youth prompted government to make it a national health priority. In South Africa, there are many efforts aimed at providing sexual and reproductive health information and services to the youth by a number of organisations. Research literature shows that young people continue to be highly vulnerable and in most cases lack sexual and reproductive health services and information. Specifically, the SYP Programme aimed at documenting and sharing knowledge and information on good practices (lessons learnt and areas of improvement) on adolescent sexual and reproductive health and rights (ASRHR) interventions and programmes, both nationally and through South-South collaboration platforms [2].

\section{Partners in sexual health}

Partners in Sexual Health (PSH), founded in September 2008, is an organisation that focuses on sexual and reproductive health, including HIV and AIDS, aimed at men, women and specifically the youth in South Africa. PSH is a Non-for-Profit Organisation (NPO), Public Benefit Organisation, constitutionally created entity according to the NPO ACT (Act Nr. 71 of 1997) of the Republic of South Africa. PSH focuses on evidence, proven effective practices, experiences, lessons learnt which are then transferred and exchanged as knowledge to improve sexual and reproductive health, including HIV and AIDS, in the South African population [4].

PSH, and specifically the Out of School Youth Project, targeted

*Corresponding author: Gerda Erasmus, Research Project Manager, Population and Development Research, Development Republic of South Africa Pretoria, Tel: +12 312 7954; +27 82 7701297; Fax: +27 86214 6637; E-mail: GerdaE@dsd.gov.za

Received July 06, 2016; Accepted May 19, 2017; Published May 26, 2017

Citation: Erasmus G, Swartz L (2017) Good Practice Case Study on HIV Prevention Treatment, Support and Care to Adolescents and Young People in the Western Cape Beaufort West, South Africa: Profiling the Out of School Youth Project of Partners in Sexual Health (PSH) Targeted at Ages 15-24. J AIDS Clin Res 8: 696. doi: 10.4172/2155-6113.1000696

Copyright: (c) 2017 Erasmus G, et al. This is an open-access article distributed under the terms of the Creative Commons Attribution License, which permits unrestricted use, distribution, and reproduction in any medium, provided the original author and source are credited. 
Citation: Erasmus G, Swartz L (2017) Good Practice Case Study on HIV Prevention Treatment, Support and Care to Adolescents and Young People in the Western Cape, Beaufort West, South Africa: Profiling the Out of School Youth Project of Partners in Sexual Health (PSH) Targeted at Ages 15-24. J AIDS Clin Res 8: 696. doi: 10.4172/2155-6113.1000696

Page 2 of 7

at ages 15-24 in Beaufort West, Western Cape, were selected to be profiled because this project addresses sexual and reproductive health issues, including HIV and AIDS needs of out-of-school youth and sensitize them on gender-based violence and substance abuse. PSH also encourages young people to access health services, including SRH services and HIV treatment. The Out of School Youth Project also strives to alleviate unemployment of young people by employing some young people as peer advisors for out-of-school youth [4].

Since 2009, PSH has implemented the Peer Education Programme in 24 schools, providing life skills, SRHR, as well as HIV and AIDS education to learners from grades 8 to 11 . School communities and school management bodies welcomed this intervention because it started to address burning social issues, such as teenage pregnancy, gender-based violence (GBV), domestic violence, gang violence, etc. Over the years, PSH has recruited and trained learners as peer educators, who in turn, impart valuable education and information to their peers in schools, and beyond. The project focussed on grade 8 and grade 10 learners, targeting them with well-structured SRHR and HIV and AIDS messages and life skills. PSH has learnt over the years that learners relate better to their peer-driven interventions. To date, they have managed to train more than 3000 peer educators, and have reached more than 150000 learners since 2009 [5].

On the other hand, the out-of-school youth, especially those who are unemployed, are at higher risk of contracting HIV and AIDS, and are most vulnerable to early and unwanted pregnancies. As a response to their vulnerability, PSH initiated the Out of School Youth Project in Beaufort West and in Khayelitsha, in Cape Town. The Out of School Project aims to capacitate out-of-school youth with life skills to deal with HIV and AIDS, while accessing health care services and negotiating safer sex [5]. The out-of-school youth and unemployed youth are vulnerable to unfavourable socio-economic and adverse health conditions, such as exposure to illicit drugs and sex trafficking and HIV infection. They are also exposed to teenage pregnancies, associated with unwanted babies. Due to their unemployment, they get involved with men who have disposable income. The young women, in particular, are not matured enough to negotiate safer sex with older men, and therefore fall prey to risky sexual behaviour [4].

The approach of PSH has been to recruit and employ matriculated young people as peer advisers. The recruits are selected from those who were trained as peer educators when they attended high school. In turn, these young people educate their peers in their respective communities.

This methodology has two main benefits, firstly, it provides parttime employment to the unemployed youth, and secondly, it utilises the skills of young people already trained as peer educators during their school years. Since the initiation of the Out of School Project in Beaufort West, PSH trained 70 of these young people. Each month they are trained on a selected SRHR topic, in accordance with South Africa's health calendar. This approach ensures that the peer advisers are abreast of any new developments in the SRH and HIV field [4,5].

\section{Objectives of the Out of School Youth Project}

The Out of School Youth Project, initiated by PSH, is aimed at the following objectives:

- to increase the knowledge of out-of-school young people in terms of HIV, SRH and sensitising and educating them on GBV and substance abuse;

- to encourage young people to share SRHR and HIV and AIDS knowledge with their peers;
- to encourage young people to access health services, including SRH services and HIV treatment;

- to reduces the risk of HIV and STI infections among young people;

- to promote HCT (HIV Counselling and Testing) uptake among out-of-school youth;

- to increase condom uptake by out-of-school youth; and

- to decrease the risk of unplanned pregnancy among young girls [6].

\section{Key Research Questions}

Given the rationale and objectives of the Out of Youth School Project, the key research questions were the following:

- What type of SRHR and HIV prevention programmes/services/ interventions are undertaken by Partners in Sexual Health (PSH), in particular the Out of Youth School project?

- What has informed the provision and uptake of these services?

- What has been the impact (both by PSH and beneficiaries) of SRHR services and interventions on improving the sexual health of young beneficiaries?

\section{Scope of the Study}

The National Population Unit (NPU), located in the Department of Social Development, conducted the research. The data collection of the Out of School Youth Project was conducted in-house. Through the adoption of a mixed-method approach, this case study was designed to be a small-scale study in order to retrieve information-rich text with depth and insight. Consequently, the proposed study does not make any attempts to generalise and reach conclusions about SRHR access and HIV prevention programmes/services/interventions on a national scale because of the limited sample.

PSH, especially through its Out of School Youth Project, targeted adolescents and young people aged between 15 and 24 in Beaufort West (Western Cape Province). They were selected to be profiled because they meet the selection criteria for a good practice case study in HIV prevention, treatment, support and care to adolescent [7].

\section{Limitations of the Case Study}

This case study applied the qualitative method and focus group discussions to elicit information from Partner in Sexual Health, particularly the Out of Youth School Project that focuses on imparting information and education to out-of-school youth on SRHR and HIV and AIDS. A short biographical questionnaire was included to illicit biographical data (part of the quantitative aspect of the study). The study outcome also depended on the honesty and openness of respondents, particularly the beneficiaries of the Out Of Youth School Project, as the information elicited will be considered personal and sensitive. The integrity of the data may be questionable since the study relied on self-reported information (by key informants), which means that information bias could occur due to overor under-reporting on attitudes and practices, as well as barriers to access to SRH services among youth [8].

\section{Research Methodology}

The following section focus on the research methodology.

\section{Research design}

A mixed research method design was selected as the preferred design 
Citation: Erasmus G, Swartz L (2017) Good Practice Case Study on HIV Prevention Treatment, Support and Care to Adolescents and Young People in the Western Cape, Beaufort West, South Africa: Profiling the Out of School Youth Project of Partners in Sexual Health (PSH) Targeted at Ages 15-24. J AIDS Clin Res 8: 696. doi: 10.4172/2155-6113.1000696

Page 3 of 7

for this good practice study as it seeks to understand the provision and uptake of SRHR services and HIV prevention programmes/services/ interventions by beneficiaries in the form of a good practice case study, amidst the backdrop of numerous social contexts [9].

\section{Methodology}

\section{Sampling and recruitment}

The non-probability purposive sampling method was used, where participation was voluntary. According to Greenstein et al. [8], this sampling method is used to target particular individuals and categories of people for investigation. Furthermore, as stated before this study is not meant to be representative, therefore the sampling was sufficient.

PSH, especially the Out of School Youth Project, targeted young people aged 15-24 in Beaufort West, were selected to be profiled because they meet the selection criteria for the inclusion as a good practice case study on HIV Prevention Treatment, Support and Care to Adolescents. The criteria for selection are the following:

- criteria on delivery of client-centred care that is sensitive to each adolescent's culture, ethnicity, community values, religion, language, educational level, sex, gender and sexual orientation;

- criteria on confidentiality; criteria on referral and follow-up systems; criteria on record keeping; criteria on monitoring and evaluation; criteria on Leadership;

- criteria on practice;

- criteria on skills and training;

- criteria on access and service provision; and

- criteria on advocacy and information sharing. (At the criteria for selection, the following scale was used; Inadequate $=1$, Fair $=2$, Good=3, Excellent $=4$ ).

Definitions for selection were the following:

- Inadequate: if an organisation has not met all criteria identified

- Fair: if an organisation meets a third of the criteria identified

- Good; if an organisation meets over half of the criteria identified

- Excellent: if an organisation meets all the criteria identified

(Total mean score $=35-40$ (Excellent), total mean score $25-34=$ Good total mean score 11-24=Fair, total mean score 0-10=inadequate) [7].

Respondents were grouped into two main groups. Each of these groups had a specific sampling strategy in accordance with the purposive sampling technique. These groups have been classified as follows:

- Primary target group: Adolescents and young people aged between 10 and 24 who are the beneficiaries of the PSH Out of youth School Project in Beaufort West;

- Secondary target group: Key informants in the form of the CEO and peer advisors who are implementers of the Out of youth School Project.

The primary target group was sourced from PSH. Recruitment and selection of the primary target group was done through snowball sampling [10].

\section{Research Methods}

Three key informants who are implementers of the Out of Youth
School Project in Beaufort West and the CEO of PSH were interviewed. Four focus group discussions were completed with beneficiaries of the Out of Youth School Project, aged between 15 and 24, namely two male and two female focus group discussions.

\section{Data Capturing and Data Analysis}

\section{Qualitative methods}

The semi-structured interviews and focus groups were transcribed and manually analysed, using thematic analysis guided by the criteria. Thematic analysis has been identified as the method of making sense of the qualitative data as it emphasizes interpretation and the discovery of meaning [10]. Central themes and patterns of difference and similarity will be elicited and explained in the context of the research findings and literature.

\section{Quantitative methods}

To compliment qualitative data, the quantitative data yielded from the brief demographic questionnaire were analysed using a software package (SPSS). Noting that the study follows a non-probability sampling method the data will be presented descriptively in the form of frequencies and percentages [8].

\section{Demographic profile of the out of school participants in Beaufort West}

Field work for the Out of School Project was concluded on 15 August 2014. Two female and two male key informants were interviewed. All the key informants were of mixed origin (Coloured: Coloured are a population group of mixed origin and are mostly residing in the Western Cape). The education level of the key informants varied from secondary education to a post graduate qualification. Two key informants indicated that they had secondary education, while one has an honours degree and another a tertiary diploma.

The majority of the participants was coloured (73\%) compared to $27 \%$ that were Black African as reflected in Figure 1. The minimum age of the recipients was 18 years old compared to the oldest recipient who was 24 years of age. The majority of the beneficiaries (31.8\%) were 19 years old (Table 1 ).

\section{Educational level}

The majority of the above-mentioned out of school recipients

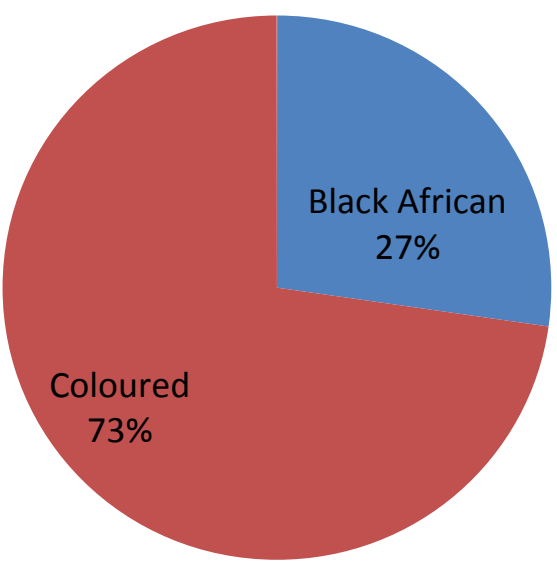

Figure 1: Population group of the recipients, 2014 
Citation: Erasmus G, Swartz L (2017) Good Practice Case Study on HIV Prevention Treatment, Support and Care to Adolescents and Young People in the Western Cape, Beaufort West, South Africa: Profiling the Out of School Youth Project of Partners in Sexual Health (PSH) Targeted at Ages 15-24. J AIDS Clin Res 8: 696. doi: 10.4172/2155-6113.1000696

Page 4 of 7

\begin{tabular}{|c|c|c|}
\hline Age & Percentage & N \\
\hline 18 years & $4.6 \%$ & 1 \\
\hline 19 years & $31.8 \%$ & 7 \\
\hline 20 years & $13.6 \%$ & 3 \\
\hline 21 years & $27.3 \%$ & 6 \\
\hline 23 years & $13.6 \%$ & 3 \\
\hline 24 years & $9.1 \%$ & 2 \\
\hline Total & $\mathbf{1 0 0 . 0}$ & $\mathbf{2 2}$ \\
\hline
\end{tabular}

Table 1: Age distribution of recipients of the out of school project, 2014.

\begin{tabular}{|c|c|c|}
\hline Sex & Percentage & N \\
\hline Female & $41 \%$ & 9 \\
\hline Male & $59 \%$ & 13 \\
\hline Total & $\mathbf{1 0 0 . 0}$ & $\mathbf{2 2}$ \\
\hline
\end{tabular}

Table 2: Sex of participants.

(95.5\%) had a secondary education and only 1 recipient indicated that he/she had a diploma. With regard to sex Table 2 illustrates that 9 of the participants was female compared to 13 that was male.

\section{Findings}

PSH is an evidence-based organisation that focuses on sexual and reproductive health including HIV/AIDS amongst all men, women and specifically the youth in South Africa [4]. In January 2009, PSH was formally established as a fully fledged non-governmental organisation. PSH focuses on evidence, proven effective practices, experiences; lessons learnt then transfer and exchange this knowledge to improve sexual and reproductive health, including HIV/AIDS amongst the South African population, specifically the youth in South Africa. The services provided by PSH include youth-friendly clinics; HIV counselling and testing; SRHR/HIV Prevention Programmes for Out of School Youth and In-School Youth; truck drivers and sex workers; SRHR advocacy and leadership training, particularly aimed at young women; teen parenting support and education to parents. Service provision is scientifically sound, non-judgmental education and counselling on sexual development and reproductive health. The vision of PSH is to pursue ongoing learning, reflection and exchange of best practices with the aim of improving sexual and reproductive health including HIV and AIDS amongst all men and women, specifically youth in South Africa. The vision, mission and focus areas of PSH is based on the National Strategic Plans of South Africa, including the current National Strategic Plan on HIV, STI and TB (NSP)2012-2016 [11]. PSH has formed partnerships and collaborated with critical role players in the Khayelitsha district, the northern sub-district and Beaufort West.

Given its public nature, PSH complies with all relevant legislations and appropriate regulations pertaining to its NPO status such as NPO Act, PFMA, Treasury Regulations and Income Tax Act to name a few legislations. Empowered and responsive decision making describes PSH governance system. PSH is autonomous with its Board of Directors providing oversight role whilst our policies serve as primary governance documents. PSH has an M\&E framework. They are also in the process of developing an electronic M\&E system in partnership with the National Planning Federation (NFP). Funders of PSH have their own approach of doing M\&E and PSH is contracted to do it according to needs of the different funders.

The M\&E framework of the Peer Educator Programme to Out of School Youth tracks financial records; generating variance reports from budgets and actual expenditures and assessing the burn rate. The nonfinancial indicators track service provision and a number of indicators stipulated in the work plan. Quality monitoring includes document audit, client exit interviews, dialogues and the use of mystery clients. The management team of head office conduct supervision visits at least quarterly. The Finance and Operational Officer conduct support visits bi-annually. Financial reporting is done on a monthly basis, while a consolidated report comprising both financial and narrative report is submitted quarterly to head office.

The findings of the research consistently indicate that Peer Advisers, group sessions of the Out of School Project and the PSH youth-friendly clinic are two of the most important sources for SRHR information and knowledge for young people in Beaufort West. Young people in Beaufort West also use the social media to source health information and track issues they are concerned about. Beneficiaries also make use of public clinics. PSH offers comprehensive SRHR trainings to the peer advisers which empowered young people to become agents of change [4].

There's a strong referral structure in place at the PSH. Databases of other services in the vicinity are kept and are used appropriately. Referrals are made by PSH peer advisers to an appropriate service provider with regards to issues raised by the youth as well as critical situations not covered in the programme. Linkages are also in place for referrals for services related to sexual violence. PSH has strong ties with all government departments, and referrals are made depending on the needs of the beneficiaries.

PSH has a huge influence in terms of the youth in the Beaufort West area. It is evident from the findings that the face-to-face sessions offered in the Out of School Project by the Peer Advisers literally saved the lives of many beneficiaries. PSH is also extending their services beyond the scope of Beaufort West. This organisation is inclusive of all applicable groups, including LGBTIs and young persons with disabilities. The young people in Beaufort West visit PSH clinics frequently and participate in all the projects offered by PSH. Although schools in Beaufort West provide the youth with some SRHR information, they are unable to provide comprehensive SRHR services to them. Schools and the parents play a key role in addressing the social and health challenges of the youth. According to the research findings it is important that schools in Beaufort West have strong linkages with and provide referrals to NGOs, clinics and health departments where youth can access these services [5]. It is also very important that young people in Beaufort West be actively involved in community projects in this area.

The beneficiaries heard about the Out of School Project from the PSH people working in the Project and the other staff from the PSH youth clinic. Other sources of information about the Out of School Project are family members and friends in the community. Peer Advisers obtain information from the clinic about the number of teenage pregnancies after which they conducted house visits to enable the youth to understand health risks and increase their SRHR knowledge.

PSH has appropriately trained leadership to ensure quality of service provision, development and training. All staff working in PSH receives appropriate training in SRHR. SRHR materials are provided at appropriate reading levels and in appropriate language(s). PSH staff constitutes of over 60 full time employees, 30 part time and interns, national and international are well trained on relevant public health issues. They have received training from recognised institutions in the Western Cape such as Simelela on Sexual Offences ACT, Faranani on Counselling, University of Cape Town on MSM, University of Stellenbosch on Sexual and Reproductive Health, Cancer Association on Reproductive Cancers, TAC HIV Treatment, ATTIC on HIV and AIDS Counselling and Testing, ACTS on ACTS model 
Citation: Erasmus G, Swartz L (2017) Good Practice Case Study on HIV Prevention Treatment, Support and Care to Adolescents and Young People in the Western Cape, Beaufort West, South Africa: Profiling the Out of School Youth Project of Partners in Sexual Health (PSH) Targeted at Ages 15-24. J AIDS Clin Res 8: 696. doi: 10.4172/2155-6113.1000696

Page 5 of 7

of HIV Counselling and Testing etc. PSH has offices in Beaufort West, Khayelitsha, Kraaifontein and Clanwilliam in the Western Cape Province, Colesberg in the Northern Cape Province, and an office in Burgersdorp in the Eastern Cape Province. PSH advisers consistently identify increased training alongside the implementation of policy and procedure as the key factors to increasing their skill and confidence level when supporting SRHR services to the out of school youth. PSH had trained 70 of these young people since its inception. SRHR education materials are provided at appropriate reading levels and in appropriate language(s). Each month, Peer Advisers are trained on a selected SRHR topic, in line with South Africa's health calendar.

\section{Discussion}

The Out of School Project originated from the In-School Project. Since 2009, PSH has implemented Peer Education Programme in 24 schools, providing life skills, SRHR and HIV and AIDS education to Learners from Grade 8 to Grade 11 [5]. School communities and school management boards welcomed this intervention because it began to address burning social issues such as teenage pregnancy, genderbased, domestic violence and gang violence, and a plethora of other social ills. After implementing the In-School Project, PSH realised that there was a huge need for SRH and comprehensive education services to out of school youth. PSH then submitted a proposal for funding, target specifically at the out-of-school youth. Their approach has been to recruit and employ matriculated young people as Peer Advisers. The recruits are selected from those who were trained as peer educators when they attended high school. These young people, in turn, educate their peers in their respective communities. This methodology has two main benefits: firstly, it provides part time employment to the unemployed youth, and secondly, it utilises the skills of young people already trained as Peer Educators during their school years. This group is one of the most marginalised and vulnerable group within the youth sector. The purpose of this project is to address the SRHR/HIV needs of young people, which include boys, girls, young men/women, young people with disabilities, young LGBTI persons, etc., who neither attended school nor had been employed [4].

Furthermore, PSH contributes to HIV/SRHR knowledge and access to services and yet alleviate the unemployment of young people by employing some young people also as peer advisers for out of school youth. PSH peer advisers takes a brief sexual history at every visit, to identify new needs for education, contraception, sexually transmitted infection (STI) including HIV screening or other services, for example, assess clients for substance use, mental health problems, interpersonal violence, and sexual abuse/assault and treat or refer for prompt treatment. Recipients are encouraged to receive screening at least once a year. Referrals are made depending on the needs of the beneficiaries [5].

The study has concluded that according to the respondents the youngsters in Beaufort West are getting sexually active earlier. The research has further established that when it comes to SRHR there is a huge need for youth friendly services and cognisance need to be taken of the needs of young people, which is not being identified and addressed fully. Issues such as unemployment/poverty and associated social skills, including drug abuse, gender based violence; gangsters; child neglect/ child abuse; crime; children not attending school/leaving school early; teenage pregnancies; HIV and AIDS, lack of SRHR information, suicide problems, etc. pose major challenges in Beaufort West [4]. These challenges has also been found in the Status of Youth Report survey [12] where it showed that young people are entering sexual relationships earlier, and that many young women, and some young men, are forced to leave school prematurely because of unwanted pregnancies. Implications of the high rate of teenage pregnancy especially among Africans and Coloureds who are already negatively affected by poverty (include dropping out of school), curtailed personal development and increased vulnerability to abusive sexual relationships. The Fourth Quarter Labour Force Survey [13] reflects the youth unemployment rate as $67.4 \%$, with young women more adversely affected than young men. According to Panday et al. [14] various life situations place girls at higher risk of becoming teen mothers. These include poverty, poor school performance and family history of teenager. Other contributory risk factors include, ignorance, curiosity, peer pressure, gender based violence, coercion and power imbalances in sexual relationships and early sexual debut [14].

Peer Advisers from the Out of School Project treated the beneficiaries with dignity and respect on their first engagement with PSH and they made to feel very comfortable to talk about anything regarding SRHR. The Peer Advisers is giving clear directions, assurance of continuing confidentiality and recommended care that includes scheduling routine follow-ups. The physical environment at PSH is also very conducive for this purpose. The quality of services rendered by the peer advisers of the out of school project is excellent. According to the key informants PSH has a standard operating procedure for the Out of School youth peer education programme. Each person reached by the PSH Peer Adviser is required to complete and sign the Peer Advisers Register. As mentioned previously, topics get chosen according to the Health Calendar. Peer advisers then receive training on the topic of the month. Referrals are made to the appropriate service provider with regards to issues raised by the youth but not covered in the programme. Peer Advisers also prepare lessons and make prior arrangements like inviting the audience/community members to different venues in the respective community. They facilitate the lesson in groups held at churches, community halls, etc.

Research findings further indicated that most parents/families recognise the importance of having accurate, SRH information. For many parents there are a desire to provide SRH information to their children but they do not know where to start, what resources to use, and is glad with the support their children receive from the peer advisers from the Out of School project to support them to make informed choices about their sexual and health-seeking behaviour and build their confidence and self-esteem.

Positives of the Out of School project for the beneficiaries were that the Out of School project has supported them to make informed choices about their sexual and health-seeking behaviour. It enable them as the youth to understand health risks; increase their SRHR knowledge, build self-esteem and skills; motivate them to keep to healthy behaviours; and improve their relationships with their parents, families and the community. They became more aware of SRH and HIV services. They felt that the programme contribute to reduce teenage pregnancy in the community and reduce the high crime rate and abuse of alcohol. The following quote reflects the participant's attitude to the Out of School project:

\section{"SRHR knowledge is power" \\ "I came here to gain knowledge on SRHR issues" \\ "You get acknowledged" \\ "I used to be shy but now I have a very good self-esteem"}


Citation: Erasmus G, Swartz L (2017) Good Practice Case Study on HIV Prevention Treatment, Support and Care to Adolescents and Young People in the Western Cape, Beaufort West, South Africa: Profiling the Out of School Youth Project of Partners in Sexual Health (PSH) Targeted at Ages 15-24. J AIDS Clin Res 8: 696. doi: 10.4172/2155-6113.1000696

Page 6 of 7

"The Out of School project has supported me to make informed choices about my sexual health"

"The project motivate me to keep to healthy behaviours"

"It's having an impact because we were staying at home and have nothing to do...but now there's the Out of School project that we are involved in and we know that as young people we are faced with certain things which we did not know about before".

(Evidence gathered from feedback received from beneficiaries attending the Out of School Project)

The counselling offered to children and teenagers who were pregnant were superb. Evidence from the findings is that the beneficiaries will recommend this service to their friends especially the Out of School project and the family planning service offered by PSH because the two programmes increase their knowledge around HIV and SRHR issues. Most of the young people surveyed are still accessing the service because the service rendered in the Out of School project provide them with comprehensive, practical and detailed information on SRHR and they can discussed any health issues they are concerned about in confidence.

It is evident from the research that PSH and especially the Out of School project are quite visible in the community and the organization play a leading role in promoting SRHR among all young people.

According to the beneficiaries of $\mathrm{PSH}$, there are still areas of improvement for the Out of School Programme. PSH could advance advocating SRHR services by addressing some language barriers for communication in the different African languages to clientele. This may mean hiring bilingual and multilingual staff and/or generously compensating staff that learn one or more additional language. Young people in Beaufort West also felt that the local community station must be utilized more to talk about the Out of School Programme, SRHR services and track issues they are concerned about. Some respondents believed that the service could be improved by having a PSH private clinic that only deals with people living with HIV who could receive counselling on a regularly basis. Beneficiaries also felt that the Out of School project must expand to more areas, because there is a need and it will attract more youth people to the programme. Findings of the research also show that respondents felt that over and above the SRH information they are getting from PSH, they also want PSH to engage the community in more drama/plays. The key informants surveyed said there is a need for managers and not only for peer advisers to be trained on certain topics of SRHR issues. More transport is needed for the managers of the Out of School Project to arrange workshops, to do face-to face interviews, etc. Churches and community leaders should be more involved in the project to grow stronger. The Out of School Project should have the support of the whole community, not just the youth. The key informants surveyed were of the opinion that there is a need for more weekend activities to keep the youngsters busy and occupied in a constructive manner.

The out of school youth is made aware that their right to confidentiality will be respected and maintained in line with the services they require, regardless of age, gender, sexual orientation, religion or ethnicity. Evident from the research is that PSH peer advisers always keep beneficiary sensitive health care issues private. The imperative need to guard the youth's confidentiality extends to every peer adviser of $\mathrm{PSH}$, including the receptionists and technicians.

Provision of youth-friendly services is a critical component of ensuring young people receive the care they want and need, whether it is sexual or mental health services. Access to such services helps young people to lead healthy and successful lives. The report provides eight essential components of PSH youth-friendly services, namely confidentiality, respectful treatment, integrated SRHR/HIV services, culturally appropriate care, diverse well-trained staff, easy access to care/swift service to the youth, free cost services and promoting parentchild communication that contributes to the youth friendliness of the out of school project [15].

Improving parent-child communication about sexuality, drug use, and other critical health issues is an important aspect of the work of the PSH peer advisers. Studies have shown that adult-focused programs and workshops can greatly strengthen parents' skills, willingness, and determination to have conversations with their teens about sex and other important health issues. Studies have showed that parents' improved communication skills resulted in better communication with their teens and improved behavioural health outcomes for youth [14-16].

The peer advisers popularise the Out of School Youth Programme through the local radio station, partnering with stakeholders, by going around the local clinics, other social media, youth gatherings at different churches and at recreational places as well as door to door activities. The peer advisers are also advocating of SRHR and HIV services for young people by distributing pamphlets, doing dramas with SRH topics. PSH works very closely with the church and are connected with the churches in Beaufort West. The active involvement with parents and other stakeholders like teachers in the Out of School project have been a critical element in creating an enabling environment and also in fostering linkages between young people and their communities.

Barriers or challenges in accessing SRHR services are the family, religion, hospital and clinic related barriers. The hospital and the clinic in Beaufort West are not youth friendly compared to the PSH youth-friendly clinic. Beneficiaries also have to wait long hours at the hospital/government clinic. Barriers to access hospital and the clinic may sometimes include: lack of transportation; not knowing where to go; hours and days when services are available; and requirements to return for follow-up [15]. According to the beneficiaries of the Out of School Project, they prefer to go to PSH for their SRH services and not the government clinic or hospital due to the confidentiality issue, friendliness, and easy access of services at PSH. Peer advisers continuously need to build a trust with the families of the beneficiaries.

While the exact impact on beneficiaries of the Out of School Project has not been measured, there is considerable evidence of a positive impact on beneficiaries as reflected by the respondent's comments. According to observations made by the key informants the uptake of the Out of School Project was excellent. Findings suggest that PSH advisers from the Out of School project was successful in supporting the young people in Beaufort West to develop confidence, knowledge and skills needed to make positive changes to protect their sexual and productive health. The Out of School Youth Peer Education Programme reached more than 30 000 out of school youth with information and skills needed to protect their SRHR and trained 70 peer advisers to implement the project [4]. Strong lasting collaborations were formed between Funders and PSH, creating a platform for activities to reach the out-of-school youth. The project proved to be a huge success in Beaufort West according to the findings and many young people came forward to join the project. The following statements reflect this sentiment:

Key informants: Assess the impact and values of the OUT of school project

"Parents play a key role in promoting SRHR. PSH held events where 
Citation: Erasmus G, Swartz L (2017) Good Practice Case Study on HIV Prevention Treatment, Support and Care to Adolescents and Young People in the Western Cape, Beaufort West, South Africa: Profiling the Out of School Youth Project of Partners in Sexual Health (PSH) Targeted at Ages 15-24. J AIDS Clin Res 8: 696. doi: 10.4172/2155-6113.1000696

Page 7 of 7

per advisers talk to the Out of School Youth and their parents. The parents sit down with the young ones and talk to them regarding sex because everything starts at home. That was a huge success for PSH”.

"PSH is making an impact in the community regarding this project. We started with the group sessions and lot of young ones are already calling from outside to ask about the project and to join"

"The Out of School project has supported the youth in Beaufort West to make informed choices about their sexual health. There are lots of success stories reported from the youth"

"The youth surveyed said the through Out of school project they have now better self-confidence and esteem, and their personal skills are more developed.

"I think we definitely have an impact on the community. We are able to encourage the youngsters who dropped out of school, because of poverty, to go back to school. We tell them to follow your dreams and go back to school...be that person that you want to be one day so that you can provide for your family."

"From my side there's a lot of change I see in a few youngsters' lives. I'm talking about some of them that we assisted two years back that are now working for Partners in Sexual Health".

Sexual and Reproductive Health and Rights (SRHR) play a major role in the lives of young people enabling them to live freely and responsibly on all aspects of their sexuality. Making SRHR a reality for young people requires the provision of youth friendly SRH services, prioritising the needs of young people, creating spaces for youth-led initiatives and increasing political commitment to youth participation in decision making processes. PSH provides the young people in Beaufort West with the tools they need to safeguard their sexual health, so that they have the responsibility to protect them from too-early childbearing and sexually transmitted infections (STIs), including HIV and Aids.

\section{Recommendations}

The following recommendations should be noted:

- Ensure that young people are involved in the design and implementation of target specific behaviour change communication interventions aimed at young people, particularly those out of schools.

- Strengthen meaningful participation of young people and youth and ensure their voices are reflected in development goals and addressed in policy responses to SRHR and HIV and AIDS.

- Develop a sustainability strategy to document lessons learnt and to share good practices with various stakeholders. This allowed reflecting upon the successes, challenges and respective solutions of the Out of School project.

- Expand service delivery. Due to the success of the Out of School project, concerted efforts should be made to reach remote and under-served areas by deputing a mobile team of peer advisers to provide SRHR services.

- At all times mobilise communities and stakeholders to support reproductive and sexual health programmes.
- Identify and capacitate the staff continuously on ongoing training regarding:

o Cultural diversity;

o Cultural norms particular to the cultures of the clients.

o Emerging issues on SRH.

\section{Conclusion}

The Out of School Project has achieved a lot in its short lifespan; and has the potential to grow extensively with sustainable funding. The energy and dedication of the staff and the partner agencies may be harnessed for the creation of an invaluable resource for the young people in Beaufort West. In addition it serves as a well-established model which has been proven in practice in the communities of Beaufort West as a good practice in meeting the challenge of HIV Prevention Treatment, Support and Care to Adolescents and Young People.

\section{References}

1. Statistics South Africa (2011) Census 2011. Government Printers: Pretoria.

2. Department of Social Development (2015) National adolescent sexual and reproductive health and rights framework strategy. Department of Social Development: Pretoria

3. Shisana OR, Simabayi T, Zuma LC, Jooste K, Pillay-van-Wyk Mbelle S, et al. (2009) South African national HIV prevalence, incidence, behaviour and communication survey 2008: A turning tide among teenagers? HSRC Press, Cape Town.

4. Partners in Sexual Health (2015) Standard operating procedure for out of school youth peer education programme. $\mathrm{PSH}$.

5. Partners in Sexual Health (2011) Sex worker peer educator training manual. Parow, $\mathrm{PSH}$.

6. Abruquah HH, Bio FY (2008) HIVIAIDS: Knowledge, attitude and practice of school adolescents in the Kwaebibliem district of Ghana. J Sci Technol 28: $1-12$.

7. Hennepin (2013) Standards of care and best practices for comprehensive adolescent sexual and reproductive health care in Hennepin County. Hennepin County, USA.

8. Greenstein R, Roberts B, Sitas A (2003) Quantitative research methods Research Methods Manual, Introduction to Quantitative Methods, pp: 1-39.

9. Tashakkori A, en Teddlie C (2003) Handbook of mixed methods in social and behavioral research. Sage, Thousand Oaks, CA.

10. Creswell JW (2009) Research design: Qualitative, quantitative and mixed method approaches. Sage, Los Angeles.

11. SANAC (2011) National Strategic Plan for HIV and AIDS, STIs and TB, 2012 20163 October 2011, Draft 1. South African National AIDS Council, Pretoria.

12. Human Sciences Research Council (2005) Status of youth report survey HSRC Printers: Pretoria.

13. Statistics South Africa (2014) Fourth quarter labour force survey. Government Printers: Pretoria.

14. Panday S, Makiwane M, Ranchod C, Letsoalo T (2009) Teenage pregnancy in South Africa - with a specific focus on school-going learners. Human Sciences Research Council. Pretoria.

15. Kaaya SF, Flisher AJ, M bwambo JK, Schaalma H, Aarø LE, et al. (2002) A review of studies of sexual behaviour of school students in sub-Saharan Africa. Scand J Public Health 30: 148-160. 